\title{
Cycle Development in a Mini-Freeze Dryer: Evaluation of Manometric Temperature Measurement in Small-Scale Equipment
}

\author{
Tim Wenzel, ${ }^{1,2}$ Margit Gieseler, ${ }^{1}$ Ahmad M. Abdul-Fattah, ${ }^{3}$ and Henning Gieseler ${ }^{1,2,4}$
}

Received 28 January 2021; accepted 6 April 2021

\begin{abstract}
The objective of this research was to assess the applicability of manometric temperature measurement (MTM) and SMART ${ }^{\mathrm{TM}}$ for cycle development and monitoring of critical product and process parameters in a mini-freeze dryer using a small set of seven vials. Freeze drying cycles were developed using SMART ${ }^{\mathrm{TM}}$ which automatically defines and adapts process parameters based on input data and MTM feedback information. The freeze drying behavior and product characteristics of an amorphous model system were studied at varying wall temperature control settings of the cylindrical wall surrounding the shelf in the mini-freeze dryer. Calculated product temperature profiles were similar for all different wall temperature settings during the MTM-SMART ${ }^{\mathrm{TM}}$ runs and in good agreement with the temperatures measured by thermocouples. Product resistance profiles showed uniformity in all of the runs conducted in the mini-freeze dryer, but absolute values were slightly lower compared to values determined by MTM in a LyoStar ${ }^{\mathrm{TM}}$ pilot-scale freeze dryer. The resulting cakes exhibited comparable residual moisture content and optical appearance to the products obtained in the larger freeze dryer. An increase in intra-vial heterogeneity was found for the pore morphology in the cycle with deactivated wall temperature control in the mini-freeze dryer. SMART ${ }^{\mathrm{TM}}$ cycle design and product attributes were reproducible and a minimum load of seven 10R vials was identified for more accurate MTM values. MTMSMART $^{\text {TM }}$ runs suggested, that in case of the wall temperature following the product temperature of the center vial, product temperatures differ only slightly from those in the LyoStar $^{\mathrm{TM}}$ freeze dryer.
\end{abstract}

KEY WORDS: freeze drying; process analytical technology; cycle development; manometric temperature measurement; scale-up.

\section{INTRODUCTION}

Due to the increasing number and spectrum of (bio)pharmaceutical and diagnostic products, freeze drying is a method of increasing importance to ensure long-term stability

$\overline{{ }^{1} \text { GILYOS GmbH, Friedrich-Bergius-Ring 15, 97076, Wuerzburg, }}$ Germany.

${ }^{2}$ Division of Pharmaceutics, Freeze Drying Focus Group, FriedrichAlexander University (FAU) Erlangen-Nürnberg, 91058, Erlangen, Germany.

${ }^{3}$ CSL Behring GmbH, Emil-von-Behring-Straße 76, 35041, Marburg, Germany.

${ }^{4}$ To whom correspondence should be addressed. (e-mail: info@gilyos.com)

Abbreviations: $A_{p}$, Ice sublimation area; $d m / d t$, Sublimation rate; $d Q$ $d t$, Heat flow into the product vial; $K_{v}$, Vial heat transfer coefficient; $L C$, LyoCapsule ${ }^{\mathrm{TM}} ; L_{d r y}$, Dry layer thickness; $L S$, LyoStar ${ }^{\mathrm{TM}} ; M T M$, Manometric temperature measurement; PAT, Process analytical technology; $P_{i c e}$, Vapor pressure of ice at sublimation interface; $R_{p}$, Dried product layer resistance; $S E M$, Scanning electron microscopy; $T_{b-M T M}$, Product temperature at vial bottom by MTM; $T_{b-T C}$, Product temperature at the vial bottom by TC; TC, Thermocouple; TDLAS, Tunable diode laser absorption spectroscopy; $T_{p-M T M}$, Product temperature at sublimation interface by MTM; $T_{s}$, Shelf temperature; $T_{\text {wall }}$, Wall temperature in the LyoCapsule ${ }^{\mathrm{TM}} ; V_{e f f}$, Effective chamber volume.

\section{ains}

Published online: 26 April 2021 
isolating the chamber from the condenser for $25 \mathrm{~s}$ (10). The resulting pressure rise curves are analyzed by non-linear regression analysis with the MTM equation which allows real-time determination of both the vapor pressure of ice at the sublimation interface $\left(\mathrm{P}_{\text {ice }}\right)$ and the resistance of the dried product layer $\left(R_{p}\right)(11)$. Based on $P_{\text {ice }}$ and $R_{p}$, data for the product temperature at the sublimation interface $\left(\mathrm{T}_{\mathrm{p}-\mathrm{MTM}}\right)$, the heat flow into the product vial $(\mathrm{dQ} / \mathrm{dt})$, the actual ice thickness, the temperature at the bottom of the vial $\left(\mathrm{T}_{\mathrm{b}-\mathrm{MTM}}\right)$, the vial heat transfer coefficient $\left(\mathrm{K}_{\mathrm{v}}\right)$, and sublimation rate $(\mathrm{dm} / \mathrm{dt})$ are instantaneously calculated by the software based on basic steady-state heat and mass transfer equations $(10,11)$. Previous studies showed good concordance of the batch-average product temperature obtained by MTM and the temperatures measured by thermocouples (TCs) until about two-thirds of primary drying in case of amorphous formulations (11). Further benefits of MTM are real-time process monitoring, instant provision of essential product information, i.e., by the $R_{p}$ profiles, and characterization of heat flow into the product (12-15). However, certain limits were also identified restricting the use for particular formulations or conditions, such as water readsorption tendencies of the dried layer during the MTM measurements using highly concentrated amorphous materials (13). Additionally, freeze dryerspecific features must be taken into consideration for reliable MTM values. Most importantly, a sufficiently fast isolation valve closing time (less than $1 \mathrm{~s}$ ), the compliance with the respective minimum load (depending on the ratio between sublimation area and effective chamber volume, $\mathrm{A}_{\mathrm{p}, \text { total }} / \mathrm{V}_{\text {eff }}$ ) and a low leak rate (below $30 \mathrm{mTorr} / \mathrm{h}$ ) are crucial for a sufficiently fast pressure rise and accurate values obtained by the curve fit $(10,13)$.

Information gained by MTM about the critical parameters and optimal process settings during a freeze drying run can be expanded by the SMART ${ }^{\text {TM }}$ feature to facilitate cycle development in one single experiment $(13,16)$. Based on selected input parameters, such as the critical formulation temperature and general formulation characteristics, the SMART $^{\mathrm{TM}}$ freeze dryer uses feedback information from MTM to maintain $\mathrm{T}_{\mathrm{p}-\mathrm{MTM}}$ below, but close to the critical formulation temperature by balancing the appropriate amount of heat through adjustment of shelf temperature $\left(\mathrm{T}_{\mathrm{s}}\right)$ and chamber pressure (17). This potential to increase cost and time efficiency is particularly useful during early development, e.g., for a new formulation or container system $(18,19)$.

A mini-freeze dryer (LyoCapsule ${ }^{\mathrm{TM}}$, SP Scientific, Gardiner, NY, USA) was developed with the objective to enable cycle development and optimization using only seven product vials, thereby limiting the financial risk during development for high-value biologics, such as antibody-drug conjugates or proteins $(20,21)$. The drying chamber of the LyoCapsule ${ }^{\mathrm{TM}}$ (LC) is composed of a small, circular shelf surrounded by a cylindrical wall and a temperature-controlled radiation plate above that can be used for stoppering similar to larger scale equipment. In addition to TC ports and pirani and capacitance manometers for pressure control, the machine can be equipped with innovative PAT tools such as tunable diode laser absorption spectroscopy (TDLAS) or MTM (22). The complementary use of the mini-freeze dryer during process development, e.g., by performing indicative experiments for novel drugs, formulations, or freeze drying configurations, offers several benefits due to the low material consumption and short preparation times. For instance, more process variables can be tested in small scale to evaluate the robustness of a formulation for cycle optimization, and troubleshooting can be performed exploiting the opportunity to scale-down a process and optimize process conditions in the small unit to avoid rejection of batches $(23,24)$. However, heat transfer differences are expected to result in atypical drying conditions (25). To provide scalable cycles, freeze drying conditions which reflect the situation in larger systems have to be created. With the aim of achieving comparable product quality, product temperature during primary drying needs to be controlled, which requires adjustment of the heat input (26). For this reason, the temperature-controlled cylindrical wall surrounding the shelf shields the vial array from radiation effects and enables modification of heat transfer by adjusting the wall temperature $\left(\mathrm{T}_{\text {wall }}\right)$ to comply with the conditions present in a larger freeze dryer. However, a downside of process development in a mini-freeze dryer is the limited number of product vials available for comprehensive analytical characterization. Therefore, reliable information about process performance and product quality obtained by innovative PAT tools is mandatory, particularly if the same PAT tools for monitoring and control are consistently deployed during development throughout different scales.

This study investigated the applicability of MTM in combination with SMART ${ }^{\mathrm{TM}}$ cycle design in miniaturized equipment for the first time. MTM data and SMART ${ }^{\mathrm{TM}}$ cycle design in the mini-freeze dryer are compared to a larger freeze dryer. In addition, the effect of the $T_{\text {wall }}$ control setting on process parameters and on the reliability of MTM values is extensively studied. To optimize the MTM procedure in the mini-freeze dryer, the impact of ice sublimation area on the accuracy of product temperature measurement is explored and limits regarding the minimum load are defined. Furthermore, the reproducibility of cycle design and MTM performance is investigated and reasons for $R_{p}$ deviations are discussed for evaluation of the reliability of this PAT tool in a small system.

\section{MATERIALS AND METHODS}

\section{Materials}

Ph. Eur. certified D(+)-sucrose was purchased from Sigma-Aldrich Chemie GmbH (Steinheim, Germany). Water for injection (B. Braun Melsungen AG, Melsungen, Germany) was used for the preparation of all solutions. TopLyo ${ }^{\circledR}$ serum tubing vials (20R and 10R) and standard serum tubing vials (4R) were obtained from Schott AG (Mainz, Germany). Westar® RS igloo stoppers were kindly provided by West Pharmaceuticals (Eschweiler, Germany). All chemicals were at least of analytical grade and used without further purification. 


\section{Methods}

\section{Preparation of Freeze Drying Cycles}

Sucrose was dissolved in water for injection at a concentration of $50 \mathrm{mg} / \mathrm{mL}$. The sample solutions were filtered using $0.45 \mu \mathrm{m}$ cellulose acetate syringe filters (VWR International, Radnor, PA, USA) prior to filling of the vials. The vials were semi-stoppered and placed on the shelves in a hexagonal packing profile. In the LyostarTM (LS) freeze dryer (SP Scientific, Gardiner, NY, USA), a stainless steel tray with a stainless steel frame was used to transfer the vials into the freeze dryer. One shelf was fully loaded with one row of empty dummy vials surrounding the product vials and acting as a thermal barrier. The bottom of the tray was removed prior to freeze drying. Additionally, aluminum foil was placed on the interior side of the front door as radiation shielding. This setup was used to reduce the edge vial effect caused by increased radiative heat transfer from the chamber door and walls $(11,27)$. Product temperature at the vial bottom was monitored using 36 gauge thin wire TCs (Omega Engineering, Newport, CT, USA). In the LC freeze dryer (SP Scientific, Gardiner, NY, USA), a ring of magnetic particles $(d=5 \mathrm{~mm})$ adjusted to the respective perimeter of the seven vial array was used to keep the vials in a hexagonal packing (Fig. 1). No further radiation shields were used in the LC.

\section{Applicability and Reproducibility of MTM-SMART ${ }^{\mathrm{TM}}$ Cycle Design in the LyoCapsule ${ }^{\mathrm{TM}}$}

Freeze drying cycles were performed using a LC minifreeze dryer. MTM-SMART ${ }^{\mathrm{TM}}$ cycles were conducted with a $50 \mathrm{mg} / \mathrm{mL}$ sucrose solution to evaluate the capability to control product temperature at a defined target temperature by adjusting $T_{\mathrm{s}}$ and chamber pressure. Three freeze drying cycles were performed to investigate the impact of $T_{\text {wall }}$ control on SMART ${ }^{\mathrm{TM}}$ performance: $\mathrm{T}_{\text {wall }}$ control was disabled (LC A), $\mathrm{T}_{\text {wall }}$ was controlled at $\mathrm{T}_{\mathrm{s}}$ ( $\mathrm{LC} \mathrm{B}$ ), and $\mathrm{T}_{\text {wall }}$ was controlled at the product temperature of the center vial as measured by TC $\left(\mathrm{T}_{\mathrm{b}-\mathrm{TC}}\right.$, center, LC C). $\mathrm{T}_{\text {wall }}$ was controlled at the respective temperatures during the entire freeze drying

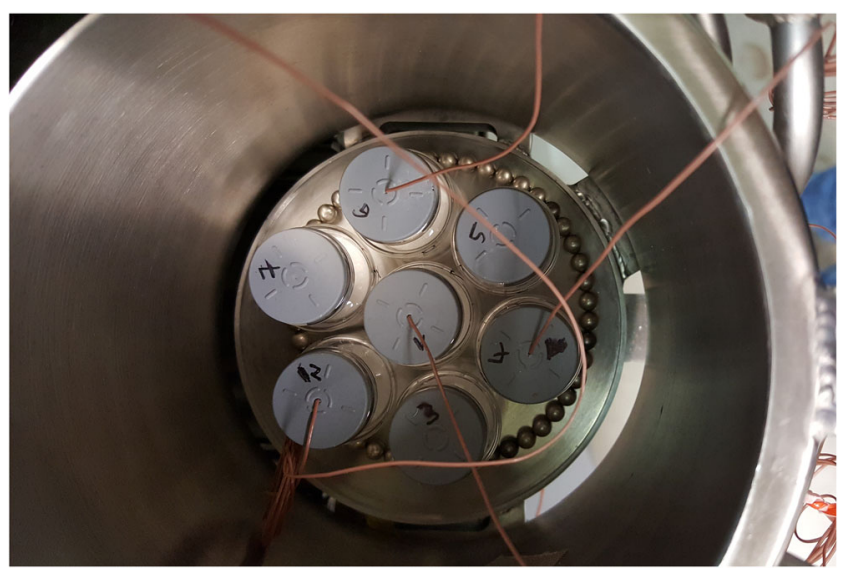

Fig. 1. Example image of the LC mini-freeze dryer shelf with a hexagonal packaging array and magnetic beads holding the vials in place. The temperature-controlled cylindrical wall can be seen surrounding the shelf cycle. $10 \mathrm{R}$ vials (ice sublimation area $\mathrm{A}_{\mathrm{p}}=3.66 \mathrm{~cm}^{2}$ ) with a fill volume of $3 \mathrm{~mL}$ were used. The collapse temperature of the sucrose solution $\left(-33^{\circ} \mathrm{C}\right)$ was determined in advance by light transmission freeze dry microscopy and used as input parameter for the SMART TM system (28-30). During primary drying, information obtained by MTM, such as dm/dt, $R_{p}, T_{p-}$ MTM, and $T_{b-M T M}$, is used as feedback information for the SMART $^{\text {TM }}$ system to optimize process conditions. MTM measurements were performed in 60-min intervals during primary drying. The temperature at the bottom of the cake was measured using three TCs placed bottom-center within the product vials (two edge vials and the center vial). The designed cycles were compared with respect to selected $T_{s}$ setpoints, average $\mathrm{T}_{\mathrm{b}-\mathrm{TC}}$, primary drying times, and MTM process data such as $T_{p-M T M}$ and $R_{p}$. The accuracy of the MTM performance was assessed by comparison of $\mathrm{T}_{\mathrm{b}-\mathrm{MTM}}$ and $\mathrm{T}_{\mathrm{b}-\mathrm{TC}}$. A reference cycle was performed in a LS pilotscale freeze dryer.

To assess the reproducibility of SMART ${ }^{\mathrm{TM}}$ cycle design (such as setpoints for $\mathrm{T}_{\mathrm{s}}$ and chamber pressure) and obtained product parameters (particularly the product temperature and $R_{p}$ profiles), triplicate SMART ${ }^{\mathrm{TM}}$ freeze drying experi-

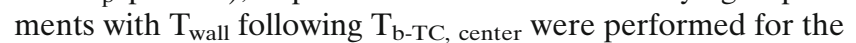
$50 \mathrm{mg} / \mathrm{mL}$ sucrose solution in $10 \mathrm{R}$ vials.

\section{Limitations of MTM Measurements in the LyoCapsule ${ }^{\mathrm{TM}}$}

By changing vial size and number, the impact of a decreasing ice sublimation area on the MTM data analysis was analyzed. Experiments in the LC were performed with different vial numbers (7 20R; 7, 5, 3 and 1 10R; 37 4R vials). This corresponded to total ice sublimation areas of 40.2, 25.6, $18.3,11.0,3.7$, and $51.8 \mathrm{~cm}^{2}$, respectively. Pressure rise curves as well as the deviations between $\mathrm{T}_{\mathrm{b}-\mathrm{MTM}}$ and $\mathrm{T}_{\mathrm{b} \text {-TC }}$ were compared for the LC cycles and a LS reference cycle with a load of 198 10R vials.

\section{Characterization of Freeze Dried Samples}

Scanning Electron Microscopy. Inner product morphology of the lyophilisates was assessed using scanning electron microscopy (SEM). Two product cakes for each batch were extracted intact from the vial by cutting the vial about $5 \mathrm{~mm}$ above the cake. The samples were split in half along the cylinder axis and sputtered twice with gold at $7 \mathrm{~mA}$ for 5 to 10 min each (Hummer Sputter System, Anatech Ltd., Union City, CA, USA). A Tescan Vegalcrxmu Scanning Electron Microscope (Brno, Czech Republic) with an acceleration voltage of $20 \mathrm{kV}$ was used to analyze the samples. SEM analysis was performed on vials without TCs. Average pore sizes along the central axis were determined by measuring ten pores near the top, middle, and bottom of the products, respectively (31).

Residual Moisture Measurement. Karl Fischer coulometric titration was used to determine residual water content. Two vials for each LC experiment and six vials for each LS experiment (three edge vials and three center vials, respectively) were used for analysis. Only non-TC vials were used for the residual moisture analysis. Between 40 and $80 \mathrm{mg}$ of sample aliquots were filled into glass vials under dry 
atmosphere (glove box, $20-25^{\circ} \mathrm{C}$, relative humidity $<1 \%$ ) and crimped. The exact sample weight was recorded by weighing the empty and filled vials using a Mettler Toledo (AT261 DeltaRange®) analytical balance. Sample vials were placed in an 874 Karl Fischer Oven Sample Processor (Metrohm, Filderstadt, Germany) at a temperature of $80^{\circ} \mathrm{C}$. The oven temperature was evaluated to be sufficient for complete water extraction of the processed freeze dried products in this study. Higher oven temperatures did not result in an increase in the extracted water content during the analysis. The water was transferred into a Karl Fischer Moisture Analyzer 831 KF (Metrohm, Filderstadt, Germany) by purging the vial headspace with dry nitrogen at $60 \mathrm{~mL} / \mathrm{min}$, and moisture content was recorded in percent. The precision of the measurement was verified using a crystalline water standard with $1 \%$ water content (Hydranal ${ }^{\mathrm{TM}}$ Water Standard KF Oven).

\section{Statistical Tests}

Statistical differences between the means of the values for the nucleation temperatures and residual moisture obtained in different freeze dryers and in the LC using different $T_{\text {wall }}$ settings, respectively, were analyzed using a 1way ANOVA test. Differences were considered statistically significant for $p \leq 0.05$.

\section{RESULTS AND DISCUSSION}

\section{MTM-SMART'M Cycle Design Using an Amorphous Excipient Solution (50 mg/mL Sucrose)}

A detailed plot of the LC B freeze drying cycle with $\mathrm{T}_{\text {wall }}$ following $T_{s}$ is shown in Fig. 2 . It should be noted that system data was exported in 1-min intervals. Because of the $25 \mathrm{~s}$ duration of the drying chamber isolation during the MTM procedure and the fast return to the chamber pressure setpoint afterwards, a pressure increase is not visible in the exported data for every MTM data point. Furthermore, the setpoints for $\mathrm{T}_{\mathrm{s}}$ and chamber pressure were chosen and adapted by the system to maintain the product temperature below the collapse temperature $\left(-33^{\circ} \mathrm{C}\right)$ throughout the process. Because of the $T_{\text {wall }}$ control setting, the $T_{\mathrm{s}}$ setpoints selected by the SMART ${ }^{\text {TM }}$ system had a direct impact on $\mathrm{T}_{\text {wall }}$. As shown in Fig. 2, $\mathrm{T}_{\mathrm{s}}$ was adjusted twice at the beginning of primary drying until reaching a final setpoint of $-24.4^{\circ} \mathrm{C}$ during steady-state conditions and this temperature was maintained until the end of primary drying. $\mathrm{T}_{\mathrm{b}-\mathrm{MTM}}$ values were consistently within $1{ }^{\circ} \mathrm{C}$ of $\mathrm{T}_{\mathrm{b} \text {-TC }}$ during the first half of primary drying. A trend towards lower $\mathrm{T}_{\mathrm{b}-\mathrm{MTM}}$ values compared to $\mathrm{T}_{\mathrm{b}-\mathrm{TC}}$ can be observed which is in agreement with the MTM bias towards the coldest vials of the batch described in the literature (11). After this period, the inaccuracy of the MTM measurements increases based on drying heterogeneity owing to a decrease of effective ice sublimation area (11). Due to the safety margin of $3^{\circ} \mathrm{C}$ the SMART ${ }^{\mathrm{TM}}$ software used, $\mathrm{T}_{\mathrm{b}-\mathrm{TC}}$ values remained at least $1.5^{\circ} \mathrm{C}$ below the collapse temperature under applied conditions confirming the capability of MTM-SMART ${ }^{\text {TM }}$ to select appropriate process conditions for this excipient solution. The endpoint of primary drying as determined by comparative pressure measurement was consistent with the decrease in $\mathrm{P}_{\text {ice }}$ to chamber pressure obtained by MTM measurements. Thus, the MTM method was sensitive enough in the minifreeze dryer to determine the primary drying endpoint and automatically select the start of secondary drying for an efficient cycle.

\section{Reproducibility of Cycle Design and Process Parameters}

The identical setting and equal input information for the software should engender comparable primary drying conditions and, in turn, provide a consistent product temperature profile and primary drying time in the triplicate reproducibility experiments. As the most challenging configuration affecting reproducibility of SMART ${ }^{\mathrm{TM}}$ constitutes the conditions in LC C $\left(\mathrm{T}_{\text {wall }}=\mathrm{T}_{\mathrm{b}-\mathrm{TC} \text {, center }}\right)$, this setup was chosen to test the reproducibility of MTM-SMART ${ }^{\mathrm{TM}}$. Potential differences in placement of the TC within the center vial may have a substantial impact on the temperature reading and, in turn, on the $\mathrm{T}_{\text {wall }}$ setting. Consequently, the heat input into the vials could be modified resulting in deviating product temperatures. The setpoints for chamber pressure and $\mathrm{T}_{\mathrm{s}}$, as well as the cycle adjustments during the first hours of primary drying selected by the SMART ${ }^{\mathrm{TM}}$ freeze dryer for the triplicate runs, showed good reproducibility (Table I). $\mathrm{T}_{\mathrm{s}}$ setpoints deviated by less than $2^{\circ} \mathrm{C}$ between the three runs, and in none of the cycles the initial chamber pressure setpoint of 57 mTorr was changed. Differences in primary drying times were negligible (approximately 6\%) between the three experiments. The comparable process conditions are expected to result in similar product temperature over time profiles. The average product temperatures deviated by less than $0.5^{\circ} \mathrm{C}$ between the three runs which is most critical for a reproducible product quality (32). It was maintained below the collapse temperature $\left(-33^{\circ} \mathrm{C}\right)$ in all cycles. $R_{p}$ profiles were consistent throughout the three runs and only negligible deviations of other MTM process data that were attributed to regular inter-batch heterogeneity were found.

\section{SMART ${ }^{\mathrm{m}}$ Cycle Design and Process Data as a Function of Different Wall Temperature Control Settings}

\section{Comparability of Temperature Profiles and Primary Drying Times}

Overlays of the $T_{b}$ profiles including applied $T_{s}$ in the MTM-SMART TM runs using different $\mathrm{T}_{\text {wall }}$ settings are shown in Fig. 3a and Table II. Owing to the strong impact of $\mathrm{T}_{\text {wall }}$ on the heat input into the product vials, $\mathrm{T}_{\mathrm{s}}$ setpoints deviated strongly between the three cycles. Whereas the initial chamber pressure setpoint of 57 mTorr was maintained unchanged, the $\mathrm{T}_{\mathrm{s}}$ setpoints differed by almost $10^{\circ} \mathrm{C}$ between the different runs using disparate $\mathrm{T}_{\text {wall }}$ control settings. The pronounced reduction of $\mathrm{T}_{\mathrm{s}}$ in $\mathrm{LC} \mathrm{A}$ with disabled $\mathrm{T}_{\text {wall }}$ control highlights the need for restraining the heat input from the shelves in order to avoid the product temperature exceeding the collapse temperature. Product temperature heterogeneity within the batch was a concern for the accuracy of the MTM measurements because of the reported bias of 


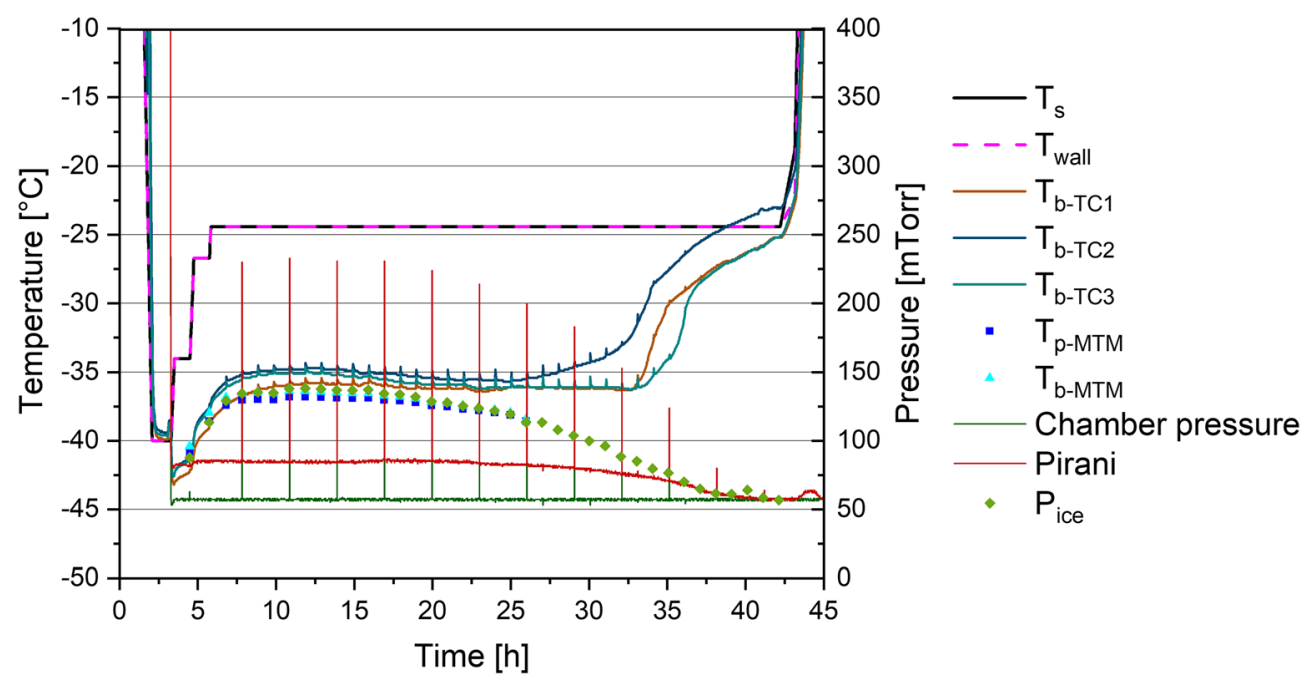

Fig. 2. Cycle design by MTM-SMARTTM for a $50 \mathrm{mg} / \mathrm{mL}$ sucrose solution in the LC mini-freeze dryer with $\mathrm{T}_{\text {wall }}$ following $\mathrm{T}_{\mathrm{s}}$ (LC B)

MTM data towards the coldest vials in a batch (11). However, despite the temperature differential of approximately $35^{\circ} \mathrm{C}$ between $T_{\text {wall }}$ and $T_{s}$ in LC A, a satisfactory homogeneity of product temperatures within the batch was found with less than $1^{\circ} \mathrm{C}$ difference between $\mathrm{T}_{\mathrm{b}-\mathrm{TC}}$, center and the surrounding edge vials. A possible explanation for this small difference could be a thermal shielding effect of the magnetic beads holding the vials in the LC in the hexagonal packaging array (Fig. 1), similar to the effect of the metal guardrail in the LS (11). This observation diminished concerns of higher inaccuracy of the MTM values due to drying heterogeneity between edge and center vials. The $T_{s}$ and $T_{\text {wall }}$ differential between the different $T_{\text {wall }}$ settings had no impact on product temperature profiles. A very good agreement of product temperatures for all conditions in the mini-freeze dryer were observed and comparability to the profiles in a larger unit was confirmed (Fig. 3a). Depending on $\mathrm{T}_{\text {wall, }}$, the cycles took around 34-39 $\mathrm{h}$ to complete and the endpoints of primary drying as measured by the decrease in $\mathrm{P}_{\text {ice }}$ to chamber pressure (MTM) were in close agreement with the comparative pressure measurement for all settings.
While the data in this study showed reasonably comparable product temperature profiles and primary drying times regardless of $\mathrm{T}_{\text {wall }}$ control, $\mathrm{T}_{\text {wall }}$ should not be reduced too far below the product temperatures. The temperature bias of MTM measurements towards cold vials is hypothesized to be caused by readsorption of water vapor from "hot vials" on "cold" vials (14). Similarly, water readsorption on the cylindrical wall surrounding the shelf and therefore an increased error in $\mathrm{T}_{\mathrm{b}-\mathrm{MTM}}$ may be expected when $\mathrm{T}_{\text {wall }}$ in the mini-freeze dryer is reduced to values too far below the product temperature of the vials.

Whereas $\mathrm{T}_{\text {wall }}$ control had a pronounced impact on process and MTM data in the LC, the impact of the wall temperature in the LS is considered negligible for this investigation. Wall temperatures during sublimation in a LS freeze dryer at $\mathrm{T}_{\mathrm{s}}=-10^{\circ} \mathrm{C}$ and $100 \mathrm{mTorr}$ chamber pressure were measured at $-10^{\circ} \mathrm{C}$ for the side walls, between -5 and $5^{\circ} \mathrm{C}$ for the back wall and between 15 and $20^{\circ} \mathrm{C}$ for the chamber door (33). The reader is advised that the side walls are not the chamber walls but the walls of the shelf stack in the LS. Consequently, most vials in the LS are only exposed

Table I. Process Conditions and Product Parameters of Triplicate MTM-SMARTтм Cycles During Steady-State Primary Drying for 3 mL 50

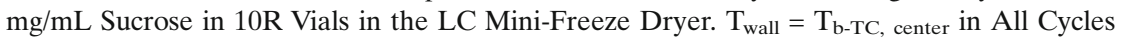

\begin{tabular}{llll}
\hline & Run 1 & Run 2 & Run 3 \\
\hline Number of vials & 7 & 7 & 7 \\
Nucleation temperature $\left[{ }^{\circ}{ }^{\mathrm{C}}\right]^{\mathrm{a}}$ & $-12.9 \pm 1.0$ & $-14.0 \pm 1.5$ & $-13.8 \pm 2.0$ \\
Primary drying time $[\mathrm{h}]$ & 35.0 & 35.1 & 33.0 \\
$\mathrm{~T}_{\mathrm{s}}(\mathrm{set})\left[{ }^{\circ} \mathrm{C}\right]$ & -20.4 & -20.9 & -19.5 \\
$\mathrm{~T}_{\mathrm{b}-\mathrm{TC}}\left[{ }^{\circ} \mathrm{C}\right]$ & $-35.4 \pm 0.5$ & $-34.6 \pm 0.5$ & $-34.5 \pm 0.4$ \\
$\mathrm{~T}_{\mathrm{p}-\mathrm{MTM}}\left[{ }^{\circ} \mathrm{C}\right]$ & $-36.8 \pm 0.1$ & $-36.7 \pm 0.1$ & $-36.7 \pm 0.2$ \\
$\mathrm{~T}_{\mathrm{b}-\mathrm{MTM}}\left[{ }^{\circ} \mathrm{C}\right]$ & $-36.3 \pm 0.1$ & $-36.3 \pm 0.1$ & $-36.2 \pm 0.2$ \\
$\mathrm{P}_{\text {ice }}[\mathrm{mTorr}]$ & $138.05 \pm 1.31$ & $139.36 \pm 1.48$ & $139.05 \pm 3.21$ \\
$\mathrm{dQ} / \mathrm{dt}[\mathrm{cal} / \mathrm{h} / \mathrm{vial}]$ & $56.25 \pm 1.81$ & $53.69 \pm 1.57$ & $59.07 \pm 2.12$ \\
$\mathrm{R}_{\mathrm{p}}\left[\mathrm{cm}{ }^{2} \rightarrow \mathrm{Torr} \rightarrow \mathrm{h} / \mathrm{g}\right]$ & $3.15 \pm 0.12$ & $3.33 \pm 0.12$ & $3.02 \pm 0.16$ \\
$\mathrm{dm} / \mathrm{dt}[\mathrm{g} / \mathrm{h} / \mathrm{vial}]$ & $0.094 \pm 0.005$ & $0.090 \pm 0.000$ & $0.100 \pm 0.000$ \\
\hline
\end{tabular}

\footnotetext{
${ }^{a} 1$-way ANOVA: $F=0.7277, p=0.5124$
} 

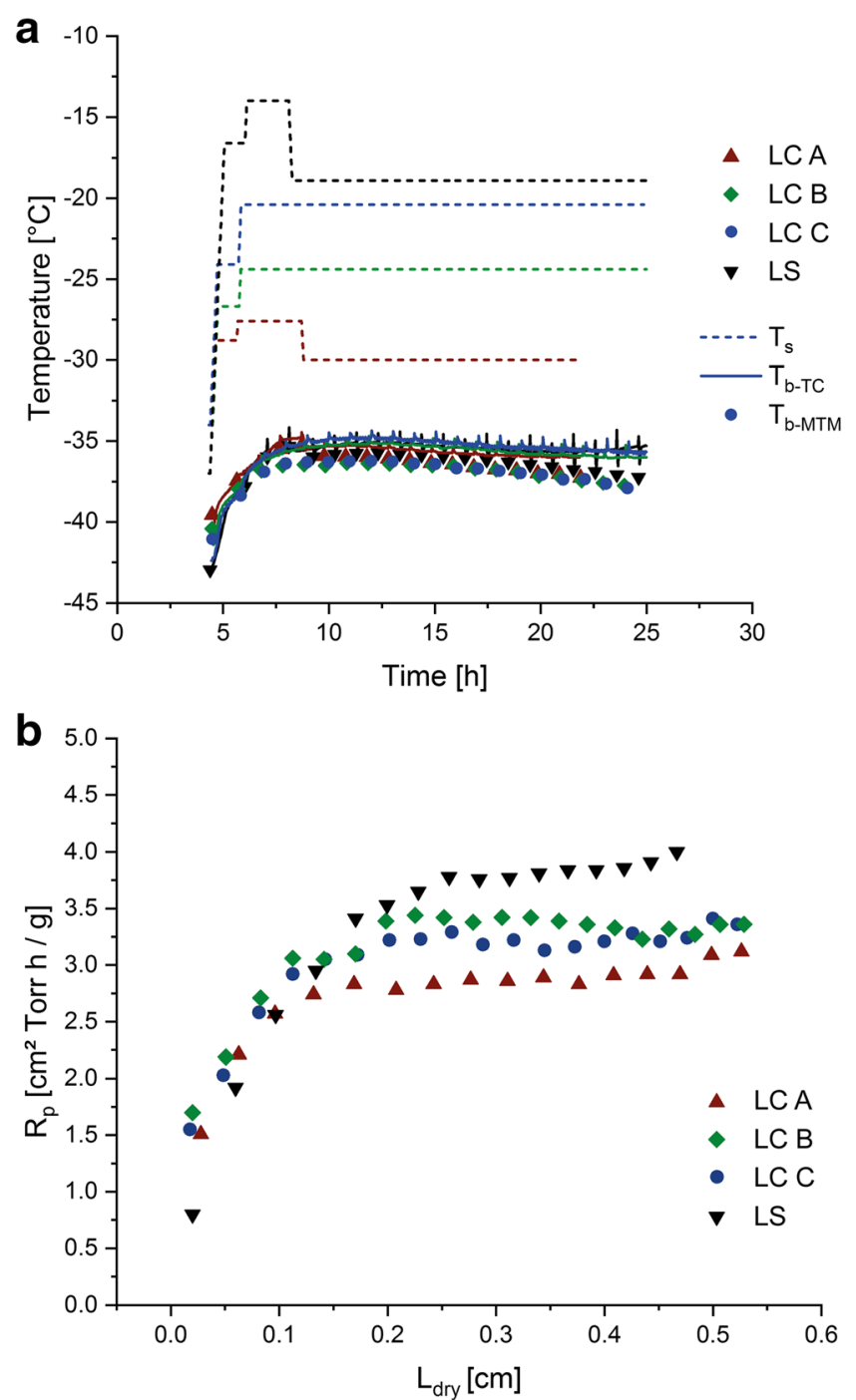

Fig. 3. a $T_{s}$ (dashed lines) and $T_{b}\left(T_{b-M T M}\right.$ : symbols; $T_{b-T C}$ : solid lines) and $\mathbf{b} \mathrm{R}_{\mathrm{p}}$ profiles from the MTM-SMART ${ }^{\mathrm{TM}}$ freeze drying cycles with different $T_{\text {wall }}$ control settings in the LC (LC A: $T_{\text {wall }}$ control disabled; $\mathrm{LC} \mathrm{B}: \mathrm{T}_{\text {wall }}=\mathrm{T}_{\mathrm{s}} ; \mathrm{LC} \mathrm{C}$ : $\mathrm{T}_{\text {wall }}=\mathrm{T}_{\mathrm{b}-\mathrm{TC} \text {, center }}$ ) and the LS reference cycle

to the side walls which have temperatures comparable to the shelf surface. Furthermore, the combination of more pronounced thermal shielding in the LS and the bias of MTM data towards the coldest or center vials of the batch further diminishes the influence of wall temperature on MTM performance in the LS (14).

Comparability of Product Resistance, Vapor Pressure of Ice, and Sublimation Rates

For all $\mathrm{T}_{\text {wall }}$ control settings, the resulting cakes exhibited a low $R_{p}$ to water vapor flow that increased non-linearly with dry layer thickness $\left(\mathrm{L}_{\mathrm{dry}}\right)$ as measured by MTM (Fig. 3b). Despite similar $\mathrm{T}_{\mathrm{b}-\mathrm{TC}}$ profiles at any given wall temperature setting, different $R_{p}$ values were observed. In addition, the profiles obtained in the LC were consistently lower compared to the $R_{p}$ profile in the LS. For example, at $L_{d r y}=0.3 \mathrm{~cm}$, the $\mathrm{R}_{\mathrm{p}}$ was $2.86 \mathrm{~cm}^{2} \times$ Torr $\times \mathrm{h} / \mathrm{g}$ in LC A, $3.42 \mathrm{~cm}^{2} \times$ Torr $\times \mathrm{h} / \mathrm{g}$ in LC B, $3.22 \mathrm{~cm}^{2} \times$ Torr $\times \mathrm{h} / \mathrm{g}$ in LC C, and $3.77 \mathrm{~cm}^{2} \times$ Torr $\times$ $\mathrm{h} / \mathrm{g}$ in the LS. Thus, $\mathrm{R}_{\mathrm{p}}$ was 1.3 times lower in LC A, 1.1 times lower in LC B, and 1.2 times lower in LC C compared to the reference value measured in the LS.

The mismatch in $\mathrm{R}_{\mathrm{p}}$ profiles - particularly between the LC A cycle with deactivated $\mathrm{T}_{\text {wall }}$ control and the LS cannot be explained by a disparity in the $\mathrm{P}_{\text {ice }}$, as these profiles showed good consistency and only slightly deviated from the $P_{\text {ice }}$ profiles of the settings with reduced $T_{\text {wall }}$ in the LC. Furthermore, nucleation temperatures were not significantly different in all experiments regardless of $T_{\text {wall }}$ control in the LC and freeze dryer (Table II) and consequently can be ruled out as a relevant factor for the observed differences as well. A possible explanation for the different $R_{p}$ profiles could be inaccuracy of MTM data because of the relatively slow pressure rise due to the low sublimation area in relation to chamber volume for all $\mathrm{T}_{\text {wall }}$ control settings. The influence of the rate of pressure increase on MTM data is further discussed in a later section of this investigation in context with the reduced load experiments. An elevated $\mathrm{dm} / \mathrm{dt}$ was observed in case of LC A. This could have been caused by increased heat transfer into the vials because of the relatively large temperature differential between $T_{\text {wall }}$ and $T_{s}$ of approximately $35^{\circ} \mathrm{C}$ in this experiment. This observation is in line with the slightly reduced primary drying time and lower average $\mathrm{R}_{\mathrm{p}}$ compared to the $\mathrm{LC} \mathrm{B}$ and $\mathrm{C}$ cycles and the cycle in the LS (34). Additionally, small differences in pore morphology as discussed in the next section may also have contributed to the lower $\mathrm{R}_{\mathrm{p}}$ values for the $\mathrm{LC} \mathrm{A}$ cycle.

\section{Characterization of Freeze Dried Products: Impact of the Wall Temperature Control on Product Quality Attributes}

As depicted in Fig. 4a-d, a certain level of shrinkage was observed for all products of the cycles using different freeze dryers and $\mathrm{T}_{\text {wall }}$ settings. This is expected behavior for sucrose solutions during freeze drying, regardless of the $\mathrm{T}_{\mathrm{s}}$ setpoint during primary drying $(35,36)$. The extent of shrinkage was comparable in all products freeze dried with different conditions. Overall cake appearance was elegant and uniform across all batches $(37,38)$.

Example SEM images for the different $T_{\text {wall }}$ control batches and the LS reference cycle are shown in Fig. $4 \mathrm{e}-\mathrm{h}$. Average pore sizes along the central axis near the top, middle, and bottom are listed in Table III. SEM analysis was particularly important for the detection of intra-vial heterogeneity. This was expected because of the varying temperature differentials between the top and bottom of the vial during freezing depending on the investigated $T_{\text {wall }}$ control settings. Product defects were not observed in the freeze dried samples. Pore sizes appeared slightly larger in the upper section of the cake in the samples processed in cycle LC A. A potential explanation for this observation could be differences in radiative heat transfer during freezing: the higher $\mathrm{T}_{\text {wall }}$ in case of LC A led to slightly higher product temperatures during freezing which could explain the larger pore sizes in the upper section of the cake. No differences in the intra-vial pore size distribution could be observed for LC $\mathrm{B}$ and LC C products with activated $\mathrm{T}_{\text {wall }}$ control or in the LS.

The similar pore structure observed in all samples was reflected by equivalent residual moisture contents suggesting comparable desorption rates during secondary drying. All 
Table II. Comparison of Product and Process Parameters During Steady-State Primary Drying of MTM-SMARTTM Runs With 3 mL 50 mg/ $\mathrm{mL}$ Sucrose Solution in $10 \mathrm{R}$ Vials Using Different $\mathrm{T}_{\text {wall }}$ Settings in the LC in Comparison to a Pilot-Scale LS Freeze Dryer

\begin{tabular}{|c|c|c|c|c|}
\hline & LS & $\begin{array}{l}\text { LC A } \\
\mathrm{T}_{\text {wall }} \text { control disabled }\end{array}$ & $\begin{array}{l}\text { LC B } \\
\mathrm{T}_{\text {wall }}=\mathrm{T}_{\mathrm{s}}\end{array}$ & $\begin{array}{l}\text { LC C } \\
\mathrm{T}_{\mathrm{wall}}=\mathrm{T}_{\mathrm{b}-\mathrm{TC}, \text { center }}\end{array}$ \\
\hline Number of vials & 198 & 7 & 7 & 7 \\
\hline Nucleation temperature $\left[{ }^{\circ} \mathrm{C}\right]^{\mathrm{a}}$ & $-11.1 \pm 3.1$ & $-13.0 \pm 1.7$ & $-13.3 \pm 2.3$ & $-12.9 \pm 1.0$ \\
\hline Primary drying time $[\mathrm{h}]$ & 37.7 & 33.8 & 38.9 & 35.0 \\
\hline $\mathrm{T}_{\mathrm{s}}(\mathrm{set})\left[{ }^{\circ} \mathrm{C}\right]$ & -18.9 & -30.0 & -24.4 & -20.4 \\
\hline $\mathrm{T}_{\text {wall }}\left[{ }^{\circ} \mathrm{C}\right]$ & - & 5.30 & -24.40 & -34.04 \\
\hline $\mathrm{T}_{\mathrm{b}-\mathrm{TC}}\left[{ }^{\circ} \mathrm{C}\right]$ & $-35.3 \pm 0.5$ & $-35.3 \pm 0.4$ & $-35.1 \pm 0.6$ & $-35.4 \pm 0.5$ \\
\hline $\mathrm{T}_{\mathrm{p}-\mathrm{MTM}}\left[{ }^{\circ} \mathrm{C}\right]$ & $-36.2 \pm 0.1$ & $-36.6 \pm 0.1$ & $-36.9 \pm 0.1$ & $-36.8 \pm 0.1$ \\
\hline $\mathrm{T}_{\mathrm{b}-\mathrm{MTM}}\left[{ }^{\circ} \mathrm{C}\right]$ & $-35.8 \pm 0.2$ & $-36.1 \pm 0.0$ & $-36.5 \pm 0.1$ & $-36.3 \pm 0.1$ \\
\hline $\mathrm{P}_{\text {ice }}[\mathrm{mTorr}]$ & $146.80 \pm 2.28$ & $141.00 \pm 2.00$ & $136.59 \pm 1.49$ & $138.05 \pm 1.31$ \\
\hline $\mathrm{dQ} / \mathrm{dt}[\mathrm{cal} / \mathrm{h} / \mathrm{vial}]$ & $55.94 \pm 0.57$ & $63.26 \pm 1.50$ & $55.13 \pm 2.60$ & $56.25 \pm 1.81$ \\
\hline $\mathrm{R}_{\mathrm{p}}\left[\mathrm{cm}^{2} \rightarrow\right.$ Torr $\left.\rightarrow \mathrm{h} / \mathrm{g}\right]$ & $3.58 \pm 0.29$ & $2.85 \pm 0.04$ & $3.28 \pm 0.18$ & $3.15 \pm 0.12$ \\
\hline $\mathrm{dm} / \mathrm{dt}[\mathrm{g} / \mathrm{h} / \mathrm{vial}]$ & $0.094 \pm 0.011$ & $0.109 \pm 0.004$ & $0.094 \pm 0.005$ & $0.094 \pm 0.005$ \\
\hline
\end{tabular}

${ }^{a}$ 1-way ANOVA: $F=0.9596, p=0.4390$

$L S$, LyoStar ${ }^{\mathrm{TM}} ; L C$, LyoCapsule ${ }^{\mathrm{TM}}$

samples of the different cycles were low in moisture content with less than $0.2 \%$ average residual moisture measured for all products (Fig. 4i). No significant differences between the freeze dryers and $\mathrm{T}_{\text {wall }}$ control settings were observed (1-way ANOVA, $F=2.3726, p=0.1106)$.

In summary, the similar product temperature profiles of all cycles in the mini-freeze dryer using active $T_{\text {wall }}$ control (LC B and C) resulted in a comparable cake appearance, pore morphology, and residual moisture content. These product quality attributes were also comparable to the products processed in a larger freeze dryer. It should be highlighted that these observations were made with a relatively simple amorphous model system. Further investigations with more complex formulations are necessary to elucidate if this conclusion is also applicable to other systems.

\section{Limitations of the MTM Technique for Use in Small-Scale Equipment}

Figure 5a shows the effect of the ice sublimation area (i.e., the number of vials) on the shape of the pressure rise curves using a $50 \mathrm{mg} / \mathrm{mL}$ sucrose solution and identical drying conditions in the LC. As clearly visible, the pressure rise curves obtained in the mini-freeze dryer showed a reduced slope compared to the reference curves in the larger freeze dryer. Particularly in case of reducing the load from seven to five or three $10 \mathrm{R}$ vials, respectively, the exponential portion was too long for a sufficient product temperature-dominated plateau phase to develop within the measurement time. In contrast, performance of a freeze drying cycle using $374 \mathrm{R}$ vials (corresponding to an ice sublimation area of $51.8 \mathrm{~cm}^{2}$ compared to $40.2 \mathrm{~cm}^{2}$ using seven $20 \mathrm{R}$ vials and $25.6 \mathrm{~cm}^{2}$ using seven $10 \mathrm{R}$ vials, respectively) resulted in a fast rise very similar to the curve progression in the pilot-scale freeze dryer.

Accurate determination of critical product and process parameters by MTM requires a sufficiently rapid chamber pressure rise during the MTM collection period (11). A too slow pressure rise may lead to a long resistance-dominated exponential pressure rise phase relative to the second, temperature-dominated phase. Consequently, the accuracy of the calculated product parameters, such as $\mathrm{T}_{\mathrm{b}-\mathrm{MTM}}$, may be impaired. For freeze drying runs in a laboratory-scale freeze dryer (FTS Dura-Stop) with a chamber volume of 52 $\mathrm{L}$, the sublimation area needs to be at least $150 \mathrm{~cm}^{2}$ corresponding to approximately $505 \mathrm{R}$ vials (11). The beta version of the LC comprises a cylindrical drying chamber with an effective chamber volume $\left(\mathrm{V}_{\text {eff }}\right)$ of $10.6 \mathrm{~L}$ determined by the pressure rise method (13). The ratio of the total ice sublimation area of all product vials to the effective chamber volume of the freeze dryer $\left(A_{p}\right.$, total $\left./ V_{e f f}\right)$ defines the required minimum product load for a reliable prediction of the product temperature by $\operatorname{MTM}(11,13)$.

The effect on the product temperature determination by MTM is illustrated in Fig. 5 b. $\mathrm{T}_{\mathrm{b}-\mathrm{MTM}}$ and $\mathrm{T}_{\mathrm{b}-\mathrm{TC}}$ were in good agreement for seven vials in the LC and a full tray of product vials in the LS. The error in the calculation of $\mathrm{T}_{\mathrm{b}-}$ MTM increases with a reduction of the ice sublimation area (e.g., a "full load" of seven 10R vials resulted in a small temperature deviation of less than $1^{\circ} \mathrm{C}$, but with decreasing load and $A_{p}$, total $/ V_{\text {eff }}$ ratio, the $T_{b}$ deviation increases to approx. $1.6^{\circ} \mathrm{C}$ for five vials, to approx. $2.7^{\circ} \mathrm{C}$ for three vials, and to more than $6^{\circ} \mathrm{C}$ for one single $10 \mathrm{R}$ vial). It should be noted that the accuracy of the $T_{b-M T M}$ and $R_{p}$ determination depends on the slope of the pressure rise curves (11). Even under full load conditions using seven vials, a relatively slow chamber pressure rise during the valve closure period is found for this model system. This could have led to a small systematic error in MTM data and may explain the discrepancies observed in the $R_{p}$ profiles between the LC cycles and the LS reference cycle discussed earlier. It is reasonable to assume that the error in MTM data will increase with formulations with higher $R_{p}$ and therefore less pronounced slopes of the pressure rise curves. The validity of MTM data should consequently even be investigated under full load conditions for formulations with higher $R_{p}$. However, endpoint detection by a decrease in $\mathrm{P}_{\text {ice }}$ was in good agreement with the endpoint by comparative pressure measurement even using a very small load of three vials suggesting a high sensitivity of measured $\mathrm{P}_{\text {ice }}$ values. 

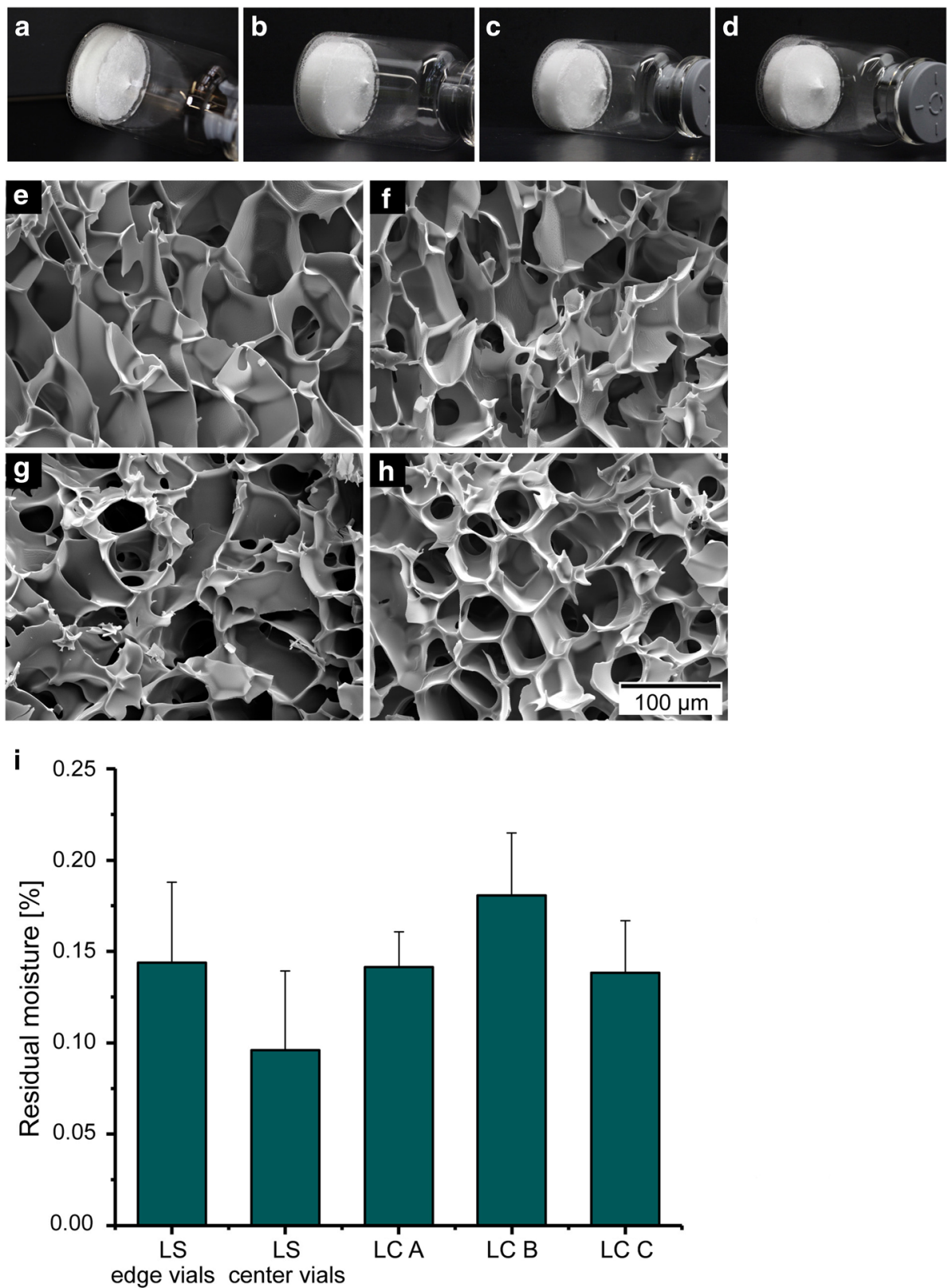

Fig. 4. a-d Product pictures and $\mathbf{e}-\mathbf{h}$ example SEM images of the middle section of products freeze dried from $10 \mathrm{R}$ vials for $50 \mathrm{mg} / \mathrm{mL}$ sucrose using different $T_{\text {wall }}$ settings in the LC compared to reference products in the LS. a, e LC A, $\mathrm{T}_{\text {wall }}$ control disabled, $\mathbf{b}, \mathbf{f} \mathrm{LC} \mathrm{B}, \mathrm{T}_{\text {wall }}=\mathrm{T}_{\mathrm{s}}, \mathbf{c}, \mathbf{g} \mathrm{LC} \mathrm{C}, \mathrm{T}_{\mathrm{wall}}$ $=\mathrm{T}_{\mathrm{b}-\mathrm{TC}}$, center $, \mathbf{d}, \mathbf{h}$ LS reference products. i Average residual moisture content of $50 \mathrm{mg} / \mathrm{mL}$ sucrose samples processed under these different conditions

Table III. Average Pore Sizes in the Center of the $50 \mathrm{mg} / \mathrm{mL}$ Sucrose Products Obtained in the LC With Different $\mathrm{T}_{\text {wall }}$ Settings in Comparison to a Pilot-Scale LS Freeze Dryer

\begin{tabular}{llllll}
\hline & LS & $\begin{array}{l}\text { LC A } \\
\mathrm{T}_{\text {wall }} \text { control disabled }\end{array}$ & $\begin{array}{l}\text { LC B } \\
\mathrm{T}_{\text {wall }}=\mathrm{T}_{\mathrm{s}}\end{array}$ & $\begin{array}{l}\mathrm{LC} \text { C } \\
\mathrm{T}_{\text {wall }}=\mathrm{T}_{\mathrm{b}-\mathrm{TC} \text {, center }}\end{array}$ \\
\hline Average pore sizes $[\mu \mathrm{m}]$ & & & $120.5 \pm 13.9$ & $88.4 \pm 15.3$ & $82.5 \pm 16.1$ \\
& Top & $94.4 \pm 11.8$ & $97.0 \pm 11.6$ & $91.8 \pm 10.2$ \\
& Middle & $105.0 \pm 10.8$ & $97.0 \pm 14.5$ & $81.5 \pm 10.4$ & $79.6 \pm 16.5$ \\
\hline
\end{tabular}

$L S$, LyoStar ${ }^{\mathrm{TM}} ; L C$, LyoCapsule ${ }^{\mathrm{TM}}$ 


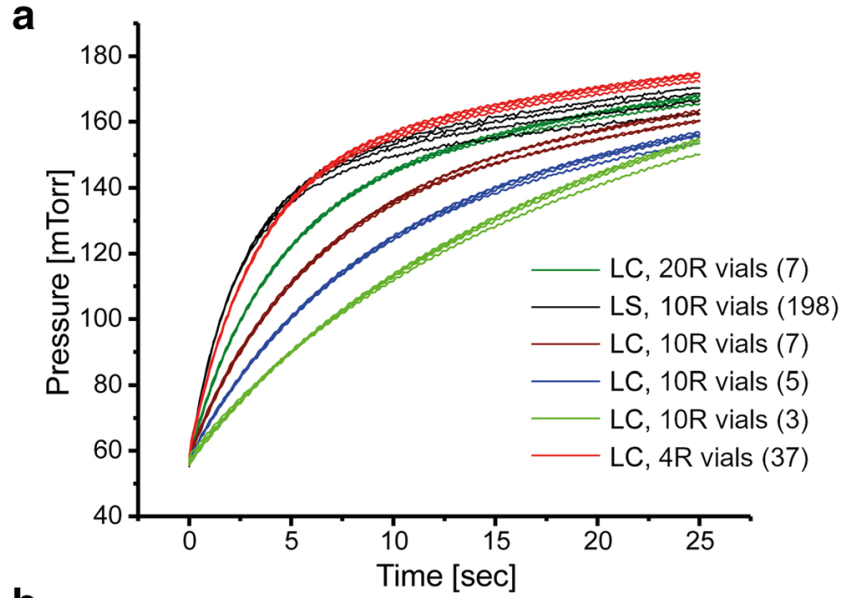

b

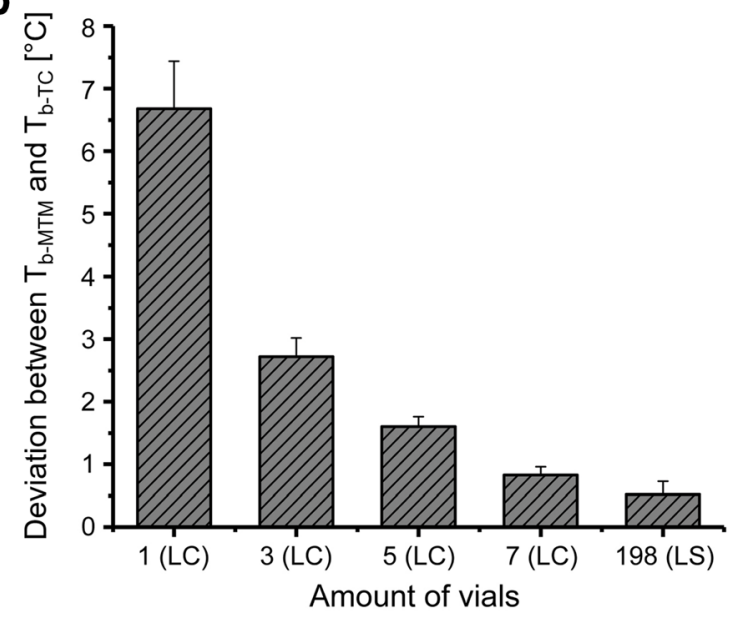

Fig. 5. a Experimental pressure rise curves for $50 \mathrm{mg} / \mathrm{mL}$ sucrose using different loading conditions and freeze dryers. The curves represent the pressure increase under steady-state primary drying conditions recorded in 0.1-s intervals. b Deviation between average $\mathrm{T}_{\mathrm{b}-\mathrm{TC}}$ and $\mathrm{T}_{\mathrm{b}-\mathrm{MTM}}$ during steady-state primary drying under different loading conditions in the LC and LS freeze dryers

The experimental results obtained support the conclusion that a minimum load of seven vials - corresponding to "full load conditions" in this small system - is imperative for accurate MTM product temperature determination in the $\mathrm{LC}$, and, in turn, reasonable SMART ${ }^{\text {TM }}$ cycle development. Thus, the minimum ratio $A_{p \text {, total }} / V_{\text {eff }}$ is calculated to be 2.4 for the $L C$, which is close to the ratio of 2.7 found for the laboratory-scale and pilot-scale freeze dryers of different sizes (Dura-Stop and LS) $(11,13)$.

Additionally, several requirements to the design and characteristics of the freeze dryer are relevant prerequisites for the use of MTM. For example, a leak rate below $30 \mathrm{mTorr} / \mathrm{h}$ is necessary for accurate calculations (13). In terms of the pressure rise curves, this is reflected by a sufficiently long plateau phase or change in slope after the initial pressure increase. If the leak rate is too high, the pressure will keep increasing too rapidly during the MTM collection period and no clear product temperaturedominated plateau phase is formed. Consequently, the non-linear regression analysis may lead to inaccurate data $(11,13)$. During the experiments performed in this study, the typical leak rate in the LC was determined to be within 25-33 mTorr/h (0.09-0.11 mTorr $\times \mathrm{L} / \mathrm{s}$ ) and thus at the upper limit for acceptable MTM performance. In contrast, leak rates measured in the LS freeze dryer were in the range of 7-10 mTorr/h $(0.33-0.47 \mathrm{mTorr} \times \mathrm{L} / \mathrm{s})$. While equipment specifications are sometimes given with the volume normalized leak rates, the absolute leak rates are important for MTM performance (13). The low chamber volume of the LC freeze dryer poses a challenge to this because the lower volume normalized leak rate translates into a more pronounced absolute pressure increase compared to larger equipment.

\section{SUMMARY AND CONCLUSION}

The present study evaluated the applicability of MTMSMART $^{\mathrm{TM}}$ for cycle development with different wall temperature control settings in the LyoCapsule ${ }^{\mathrm{TM}}$ mini-freeze dryer and compared process data and product quality attributes to a pilot-scale freeze dryer. A reasonable SMART ${ }^{\mathrm{TM}}$ cycle development was demonstrated for various wall temperature settings, and good agreement of the vapor pressure of ice with comparative pressure measurement for endpoint detection was found. Additionally, calculated $\mathrm{T}_{\mathrm{b}-\mathrm{MTM}}$ profiles showed a good conformity with the temperatures measured by temperature probes under different conditions, and reproducibility of the process and product parameters was confirmed. Control of the wall temperature at values equivalent to the product temperature of vials during primary drying led to comparable process data and product quality attributes of a $50 \mathrm{mg} / \mathrm{mL}$ sucrose system in both scales. Considering the minimum load requirement of seven $10 \mathrm{R}$ vials and a regular testing of the leak rate, the mini-freeze dryer with MTMSMART $^{\mathrm{TM}}$ can be used irrespective of the wall temperature settings for substantial time and resource savings during early development and optimum data comparability during scaleup to larger equipment.

\section{Abbreviations}

\section{ACKNOWLEDGEMENTS}

Christian Schulbert, GeoZentrum Nordbayern, Section Palaeontology, Erlangen, Germany, is gratefully acknowledged for assistance with SEM measurements.

\section{FUNDING}

Open Access funding enabled and organized by Projekt DEAL.

Open Access This article is licensed under a Creative Commons Attribution 4.0 International License, which permits use, sharing, adaptation, distribution and reproduction in any medium or format, as long as you give appropriate credit to the original author(s) and the source, provide a link to the Creative Commons licence, and indicate if changes were made. The images or other third party material in this article are included in the article's Creative Commons licence, unless indicated otherwise in a credit line to the material. If material is not included in the article's Creative Commons licence and your intended use is not permitted by statutory regulation or exceeds the permitted use, you will need to obtain permission directly from the copyright holder. To view a copy of this licence, visit http:// creativecommons.org/licenses/by/4.0/. 


\section{REFERENCES}

1. Schwegman JJ, Hardwick LM, Akers MJ. Practical formulation and process development of freeze-dried products. Pharm Dev Technol. 2005;10(2):151-73. https://doi.org/10.1081/PDT-56308.

2. Manning MC, Patel K, Borchardt RT. Stability of protein pharmaceuticals. Pharm Res. 1989;6(11):903-18. https://doi.org/ 10.1023/a:1015929109894.

3. Tang X, Pikal MJ. Design of freeze-drying processes for pharmaceuticals: practical advice. Pharm Res. 2004;21(2):191200. https://doi.org/10.1023/b:pham.0000016234.73023.75.

4. Abdul-Fattah AM, Truong-Le V, Yee L, Pan E, Ao Y, Kalonia DS, et al. Drying-induced variations in physico-chemical properties of amorphous pharmaceuticals and their impact on stability II: stability of a vaccine. Pharm Res. 2007;24(4):71527. https://doi.org/10.1007/s11095-006-9191-2.

5. Luthra S, Obert JP, Kalonia DS, Pikal MJ. Investigation of drying stresses on proteins during lyophilization: differentiation between primary and secondary-drying stresses on lactate dehydrogenase using a humidity controlled mini freeze-dryer. J Pharm Sci. 2007;96(1):61-70. https://doi.org/10.1002/jps.20758.

6. Obeidat WM, Sahni E, Kessler W, Pikal M. Development of a mini-freeze dryer for material-sparing laboratory processing with representative product temperature history. AAPS PharmSciTech. 2018;19(2):599-609. https://doi.org/10.1208/ s12249-017-0871-5.

7. Schneid SC, Johnson RE, Lewis ML, Stärtzel P, Gieseler H. Application of process analytical technology for monitoring freeze-drying of an amorphous protein formulation: use of complementary tools for real-time product temperature measurements and endpoint detection. J Pharm Sci. 2015;104(5):1741-9. https://doi.org/10.1002/jps.24389.

8. Kramer T, Kremer DM, Pikal MJ, Petre WJ, Shalaev EY, Gatlin LA. A procedure to optimize scale-up for the primary drying phase of lyophilization. J Pharm Sci. 2009;98(1):307-18. https:// doi.org/10.1002/jps.21430.

9. Schneid SC, Gieseler H, Kessler WJ, Pikal MJ. Non-invasive product temperature determination during primary drying using tunable diode laser absorption spectroscopy. J Pharm Sci. 2009;98(9):3406-18. https://doi.org/10.1002/jps.21522.

10. Milton N, Pikal MJ, Roy ML, Nail SL. Evaluation of manometric temperature measurement as a method of monitoring product temperature during lyophilization. PDA J Pharm Sci Technol. 1997;51(1):7-16.

11. Tang X, Nail SL, Pikal MJ. Evaluation of manometric temperature measurement, a process analytical technology tool for freeze-drying: part I, product temperature measurement. AAPS PharmSciTech. 2006;7(1):E14. https:// doi.org/10.1208/pt070114.

12. Overcashier DE, Patapoff TW, Hsu CC. Lyophilization of protein formulations in vials: investigation of the relationship between resistance to vapor flow during primary drying and small-scale product collapse. J Pharm Sci. 1999;88(7):688-95. https://doi.org/10.1021/js980445+.

13. Gieseler H, Kramer T, Pikal MJ. Use of manometric temperature measurement (MTM) and SMART'M freeze dryer technology for development of an optimized freeze-drying cycle. J Pharm Sci. 2007;96(12):3402-18. https://doi.org/10.1002/jps.20982.

14. Tang XC, Nail SL, Pikal MJ. Evaluation of manometric temperature measurement, a process analytical technology tool for freeze-drying: part II measurement of dry-layer resistance. AAPS PharmSciTech. 2006;7(4):E77-84. https://doi.org/10.1208/ pt070493.

15. Tang XC, Nail SL, Pikal MJ. Evaluation of manometric temperature measurement (MTM), a process analytical technology tool in freeze drying, part III: heat and mass transfer measurement. AAPS PharmSciTech. 2006;7(4):E10511. https://doi.org/10.1208/pt070497.

16. Tang XC, Nail SL, Pikal MJ. Freeze-drying process design by manometric temperature measurement: design of a smart freeze-dryer. Pharm Res. 2005;22(4):685-700. https://doi.org/ 10.1007/s11095-005-2501-2.
17. Johnson RE, Oldroyd ME, Ahmed SS, Gieseler H, Lewis LM. Use of manometric temperature measurements (MTM) to characterize the freeze-drying behavior of amorphous protein formulations. J Pharm Sci. 2010;99(6):2863-73. https://doi.org/ 10.1002/jps.22031.

18. Patel SM, Pikal MJ. Freeze-drying in novel container system: characterization of heat and mass transfer in glass syringes. J Pharm Sci. 2010;99(7):3188-204. https://doi.org/10.1002/ jps.22086.

19. Korpus C, Pikal M, Friess W. Heat transfer analysis of an optimized, flexible holder system for freeze-drying in dual chamber cartridges using different state-of-the-art PAT tools. J Pharm Sci. 2016;105(11):3304-13. https://doi.org/10.1016/ j.xphs.2016.07.005.

20. Colandene JD, Maldonado LM, Creagh AT, Vrettos JS, Goad KG, Spitznagel TM. Lyophilization cycle development for a high-concentration monoclonal antibody formulation lacking a crystalline bulking agent. J Pharm Sci. 2007;96(6):1598-608. https://doi.org/10.1002/jps.20812.

21. Wang DQ, Hey JM, Nail SL. Effect of collapse on the stability of freeze-dried recombinant factor VIII and alpha-amylase. J Pharm Sci. 2004;93(5):1253-63. https://doi.org/10.1002/jps.20065.

22. Nail S, Tchessalov S, Shalaev E, Ganguly A, Renzi E, Dimarco $\mathrm{F}$, et al. Recommended best practices for process monitoring instrumentation in pharmaceutical freeze drying-2017. AAPS PharmSciTech. 2017;18(7):2379-93. https://doi.org/10.1208/ s12249-017-0733-1.

23. Schneid SC, Stärtzel PM, Lettner P, Gieseler H. Robustness testing in pharmaceutical freeze-drying: inter-relation of process conditions and product quality attributes studied for a vaccine formulation. Pharm Dev Technol. 2011;16(6):583-90. https:// doi.org/10.3109/10837450.2011.581287.

24. Chen X, Sadineni V, Maity M, Quan Y, Enterline M, Mantri RV. Finite element method (FEM) modeling of freeze-drying: monitoring pharmaceutical product robustness during lyophilization. AAPS PharmSciTech. 2015;16(6):1317-26. https:// doi.org/10.1208/s12249-015-0318-9.

25. Goldman JM, Chen X, Register JT, Nesarikar V, Iyer L, Wu Y, et al. Representative scale-down lyophilization cycle development using a seven-vial freeze-dryer (MicroFD $\left.{ }^{\circledR}\right)$. J Pharm Sci. 2019;108(4):1486-95. https://doi.org/10.1016/j.xphs.2018.11.018.

26. Patel SM, Pikal MJ. Emerging freeze-drying process development and scale-up issues. AAPS PharmSciTech. 2011;12(1):3728. https://doi.org/10.1208/s12249-011-9599-9.

27. Rambhatla S, Pikal MJ. Heat and mass transfer scale-up issues during freeze-drying, I: atypical radiation and the edge vial effect. AAPS PharmSciTech. 2003;4(2):22-31. https://doi.org/ $10.1208 /$ pt040214.

28. Meister E, Gieseler H. Freeze-dry microscopy of protein/sugar mixtures: drying behavior, interpretation of collapse temperatures and a comparison to corresponding glass transition data. J Pharm Sci. 2009;98(9):3072-87. https://doi.org/10.1002/jps.21586.

29. Meister E, Šaši S, Gieseler H. Freeze-dry microscopy: impact of nucleation temperature and excipient concentration on collapse temperature data. AAPS PharmSciTech. 2009;10(2):582-8. https://doi.org/10.1208/s12249-009-9245-y.

30. Pikal MJ, Shah S. The collapse temperature in freeze drying: dependence on measurement methodology and rate of water removal from the glassy phase. Int J Pharm. 1990;62(2-3):16586. https://doi.org/10.1016/0378-5173(90)90231-R.

31. Oddone I, Van Bockstal PJ, De Beer T, Pisano R. Impact of vacuum-induced surface freezing on inter- and intra-vial heterogeneity. Eur J Pharm Biopharm. 2016;103:167-78. https:// doi.org/10.1016/j.ejpb.2016.04.002.

32. Passot S, Fonseca F, Barbouche N, Marin M, Alarcon-Lorca M, Rolland D, et al. Effect of product temperature during primary drying on the long-term stability of lyophilized proteins. Pharm Dev Technol. 2007;12(6):543-53. https://doi.org/10.1080/ 10837450701563459.

33. Pikal MJ, Bogner R, Mudhivarthi V, Sharma P, Sane P. Freezedrying process development and scale-up: scale-up of edge vial versus center vial heat transfer coefficients, $\mathrm{K}_{\mathrm{v}}$. J Pharm Sci. 2016;105(11):3333-43. https://doi.org/10.1016/j.xphs.2016.07.027.

34. Kodama T, Sawada H, Hosomi H, Takeuchi M, Wakiyama N, Yonemochi E, et al. Determination for dry layer resistance of 
sucrose under various primary drying conditions using a novel simulation program for designing pharmaceutical lyophilization cycle. Int J Pharm. 2013;452(1-2):180-7. https://doi.org/10.1016/ j.ijpharm.2013.04.081.

35. Rambhatla S, Obert JP, Luthra S, Bhugra C, Pikal MJ. Cake shrinkage during freeze drying: a combined experimental and theoretical study. Pharm Dev Technol. 2005;10(1):33-40. https:// doi.org/10.1081/pdt-35871.

36. Ullrich S, Seyferth S, Lee G. Measurement of shrinkage and cracking in lyophilized amorphous cakes. Part I: final-product assessment. J Pharm Sci. 2015;104(1):155-64. https://doi.org/ 10.1002/jps.24284.
37. Patel SM, Nail SL, Pikal MJ, Geidobler R, Winter G, Hawe A, et al. Lyophilized drug product cake appearance: what is acceptable? J Pharm Sci. 2017;106(7):1706-21. https://doi.org/ 10.1016/j.xphs.2017.03.014.

38. Haeuser C, Goldbach P, Huwyler J, Friess W, Allmendinger A. Imaging techniques to characterize cake appearance of freezedried products. J Pharm Sci. 2018;107(11):2810-22. https:// doi.org/10.1016/j.xphs.2018.06.025.

Publisher's Note Springer Nature remains neutral with regard to jurisdictional claims in published maps and institutional affiliations. 